\title{
PENGARUH NORMALIZING TERHADAP BAJA 20Mn Cr6 HASIL PENGECORAN UNTUK SUPPORT ROLLER
}

\author{
Yusril Irwan dan M. Roedal Patriot \\ Jurusan Teknik Mesin, Fakultas Teknologi Industri \\ Institut Teknologi Nasional Bandung \\ e-mail: yusrilirwan1@gmail.com
}

\begin{abstract}
Rotary Kiln machine is used in fertilizer plant which is function to mix the fertilizer ingredients. Part of the Rotary Kiln is support by using a roller. Support roller is made of $20 \mathrm{MnCr} 6$ material, AISI 5120 (0.18\% C) with casting process. Normalizing phase on casting processes is using to increase strength of the material The objectives of the normalizes process is to eliminate residual stresses, softening, increasing toughness, homogenization of micro structures and to ease machining processes. The effect of normalizing can be measured by using mechanical test, ie tensile test, hardness test and microstructure analysis. Test specimens were made the same material with normalizing and without normalizing process. Normalizing process temperature at $900^{\circ} \mathrm{C}$ heating for 150 minutes with air cooling for 7 hours. The results has shown that normalizing material has lowest tensile strength of 41.05 $\mathrm{kg} / \mathrm{mm}^{2}$ is compared to $42.16 \mathrm{kgf} / \mathrm{mm}^{2}$. However, the ductile fracture is higher $41.2 \%$ is compared to $29.52 \%$, the microstructure formed uniformly evenly compared without normalizing. The softening process also makes the roller support rotate due to rubbing with riding ring.
\end{abstract}

Keywords: Support Roller, Normalizing, tensile test.

\section{PENDAHULUAN}

PT. XXXX merupakan perusahaan yang memproduksi pupuk, dimana pengolahan dilakukan dengan mesin Rotari Kiln. Salah satu komponennya yaitu support roller yang berfungsi sebagai tumpuan. Support Roller harus kuat dan tahan aus tapi tidak lebih kuat dari riding ring demi memudahkan pembaharuan dari Rotary Kiln seperti pada Gambar 1. Maka pemilihan material yang cocok agar sesuai dengan kebutuhan, karna jika tidak, akan membuat kinerja mesin tidak optimal. Proses pembuatan dari support roller yaitu dengan pengecoran logam (metal casting) yang kemudian dihaluskan permukaannnya melalui proses pemesinan. Proses tersebut dipilih dengan menimbang aspek dimensi roller yang cukup besar serta desain sederhana. Material [OEM (Original Equipment Manufacture)] yang dipilih untuk pembuatan support roller adalah 20MnCr6,AISI $5120(0.18 \% \mathrm{C})$ yang merupakan baja karbon rendah, komposisi kimia dari materialnya dapat di lihat pada Tabel 1. Baja karbon rendah dipilih agar kekuatan roller lebih rendah dari riding rings demi memudahkan pembaharuan dari Rotary Kiln.

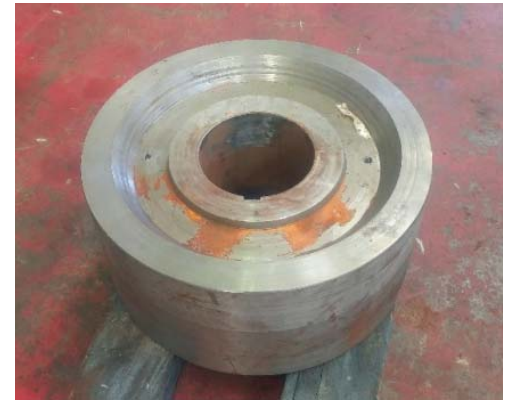

a. Support Roller

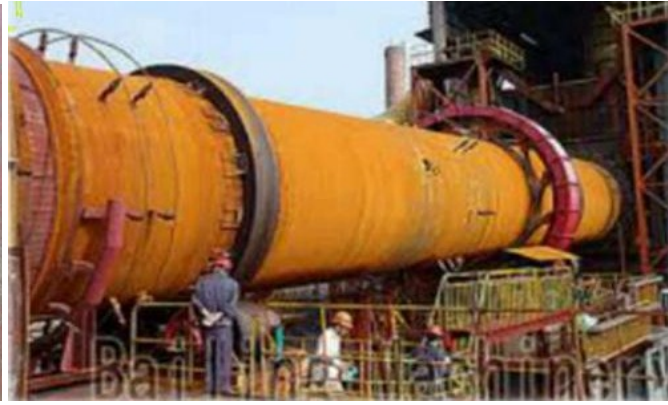

b. Rotary Kiln

Gambar 1. Susunan rotary kiln dan support roller

Hasil proses pengecoran memiliki sifat yang getas dan mampu mesin yang rendah. Untuk meningkatkan ketangguhan dan memperbaiki sifat mampu mesin Support Roller, harus dilakukan proses perlakuan panas. Proses perlakuan panas yang di pilih adalah normalizing, untuk memperbaiki sifat dari support roller agar sesuai dengan kebutuhan. Untuk itu perlu dilakukan analisis pengaruh normalizing terhadap sifat mekanik melalui pengujian mekanikal. Pengujian 
dilakukan pada spesimen dengan bahan dan proses pembuatan yang sama dengan Support Roller.Spesimen diproses dengan normalizing dan tanpa normalizing untuk melihat perbandingan hasil. Pengujian mekanikal yang dilakukan yaitu uji tarik, uji keras dan analisis stuktur mikro bedasarkan standar pengujian masing-masing untuk melihat pengaruh dari proses normalizing tersebut.

Pengujian tarik dilakukan untuk melihat kekuatan tarik serta elongasi untuk dua spesimen yang berbeda perlakuan. Pengujian kekerasan dilakukan untuk melihat pengaruh normalizing terhdap nilai kekerasan, lalu analisis struktur mikro bertujuan untuk melihat perubahan struktur setelah support roller dinormalizing.

Tabel 1. Tabel standar material

\begin{tabular}{|c|c|c|c|c|c|c|c|c|c|}
\hline \multirow{2}{*}{ Material } & \multirow{2}{*}{ Besi Scrap } & \multirow{2}{*}{$\begin{array}{c}\text { Return } \\
\text { Scrap }\end{array}$} & \multicolumn{7}{|c|}{ Standar Komposisi Tambahan } \\
\hline & & & $\mathbf{C}$ & Si & Mn & $\mathbf{P}$ & $\mathbf{S}$ & $\mathbf{C r}$ & $\mathbf{N i}$ \\
\hline $\begin{array}{c}\text { DIN } \\
\text { 20MnCr6 }\end{array}$ & $900 \mathrm{Kg}$ & - & $\begin{array}{c}0,18 \% \\
\operatorname{Max}\end{array}$ & $\begin{array}{l}0,4 \% \\
\operatorname{Max}\end{array}$ & $\begin{array}{l}1,15 \% \\
\text { Max }\end{array}$ & $\begin{array}{l}0,04 \% \\
\text { Max }\end{array}$ & $\begin{array}{c}0,04 \% \\
\operatorname{Max}\end{array}$ & $\begin{array}{c}1,15 \% \\
\operatorname{Max}\end{array}$ & $\begin{array}{l}0,3 \% \\
\text { Max }\end{array}$ \\
\hline
\end{tabular}

Support roller harus lebih lunak dari riding ring agar terjadi gesekan yang memungkinkan rotary kiln berputar sebagai pengaduk pupuk. Dengan melihat segi disain sederhana serta ukuran dimensi yang cukup besar dipilihlah proses sand casting.

\section{Proses Pengecoran}

Proses pengecoran support roller dilakukan di Divisi Foundry PT. XXXX, dimana pada proses ini dimulai dari pembuatan pola yang terbuat dari kayu. Dari pola lalu ke tahap moulding untuk membuat cetakan pasir sekaligus pembuatan gating system. Setelah cetakan pasir selesai, logam bahan pengecoran dilebur sesuai dengan komposisi kimia yang sesuai standar (DIN 20MnCr6). Untuk menentukan komposisi kimia dilakukan pengujian spektrometer di lab. Metalurgi PT. XXX, jika komposisi belum tercapai maka dilakukan penambahan komposisi pada temperatur lebur yang sama cair dituang kedalam cetakan pasir. Pada saat penuangan ladle harus dibakar agar dalam kondisi kering tujuannya menghilangkan kelembaban pada ladle. Kelembaban dapat menghasilkan letupan dan juga menghindari penurunan temperatur [1]. Setelah dituang ke cetakan material di dinginkan sekitar 12 jam hingga terjadi pembekuan (frosting). Pembekuan akan dimulai dari permukaan casting menuju kebawah permukan, hal ini terjadi karna perbedaan temperatur [1]. Setelah pembekuan selesai, hasil casting dipisahkan dari cetakan menggunakan mesin shake out, namun karna dimensi dari casting melebihi kapasitas mesin maka pelepasan cetakan dilakukan manual. Hasil casting sudah lepas dari cetakan memiliki gating system yang masing terpasang. Gating system dilepas/dipotong menggunkan gerinda potong, lalu dilakukan normalizing setelah casting diproses shoot blasting.Shoot blasting dilakukan untuk memuang sisa pasir yang menempel pada casting serta mengurangi tegangan sisa yang terjadi. Proses pemesinan bertujuan untuk mencapai dimensi yang diinginkan, karena dalam pengecoran logam dimensi dari casting berukuran lebih besar daripada ukuran operasional dari support roller. Untuk mencapai dimensi tersebut support roller di machining dengan proses bubut unutuk membuat memperhalus permukaan, membuat dimensi luar/dalam dan dalam. Proses pemesinan selanjutnya yaitu slotting bertujuan untuk membuat slot untuk poros dari support roller. Setelah itu support roller siap dipasang di pabrik X PT. XXX. Berikut urutan pembuatan support roller seperti pada Gambar 2. 


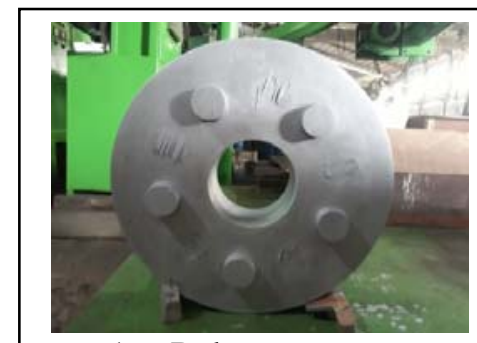

1. Pola

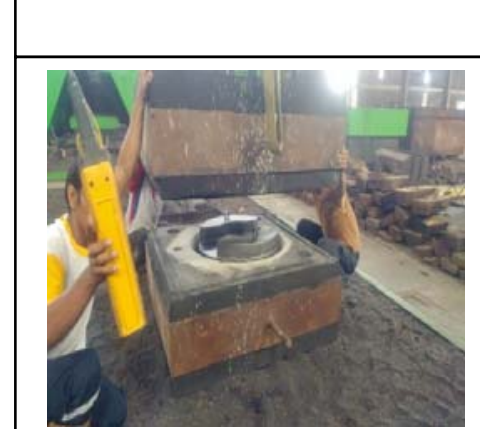

4. Assembly
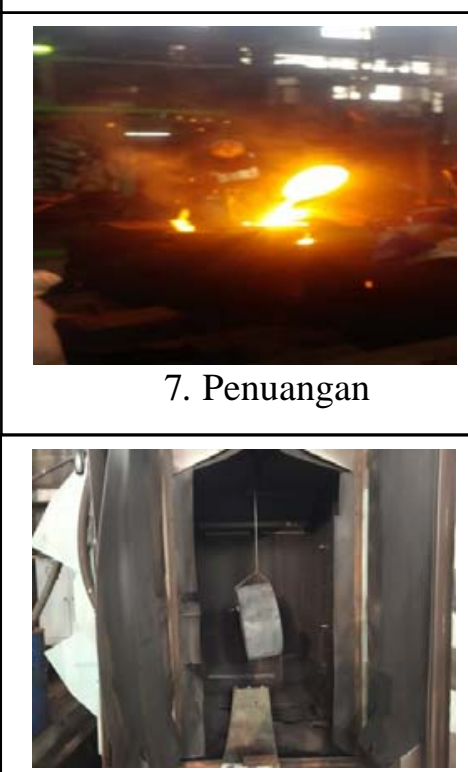

10. Shoot Balsting

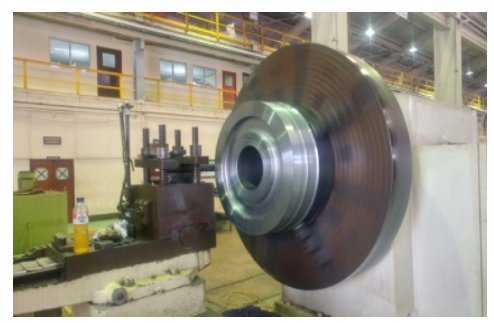

12. Proses Pemesinan

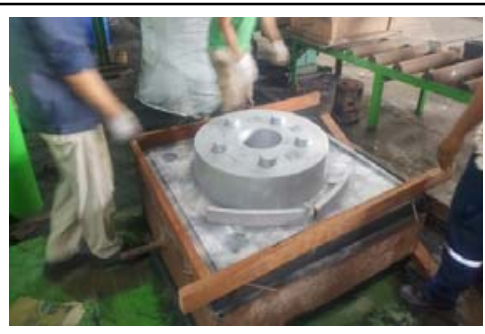

3. Moulding

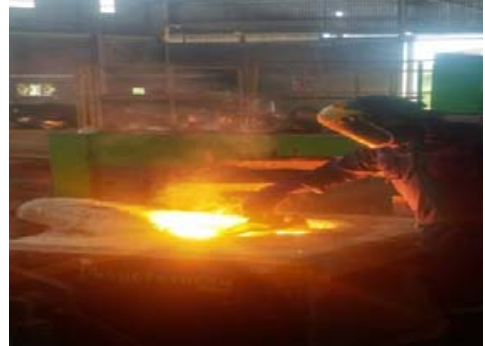

5. Melting

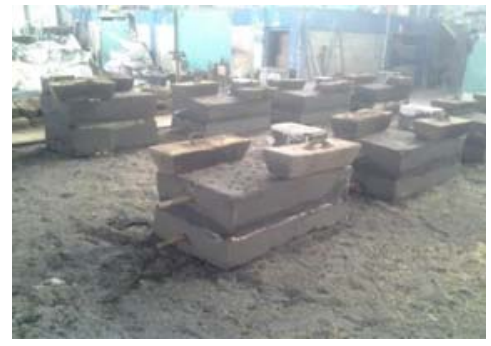

8. Pembekuan

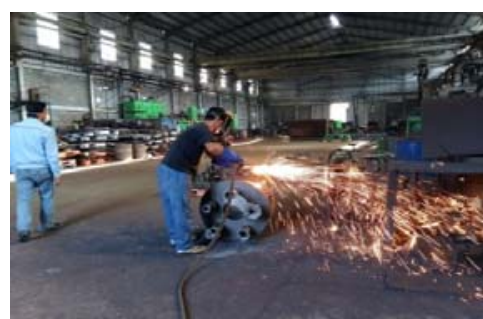

11. Fetling

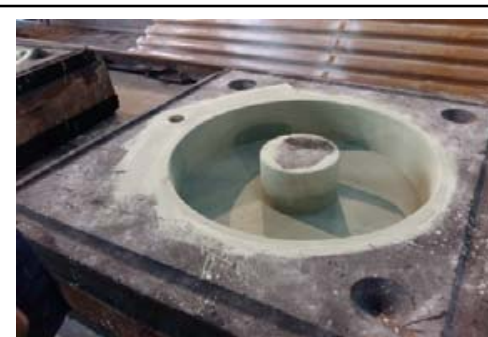

2. Coating

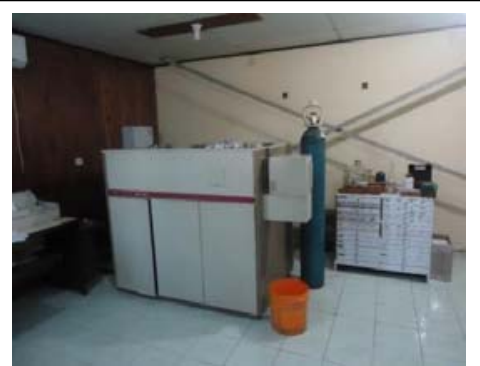

6. Spectrometri

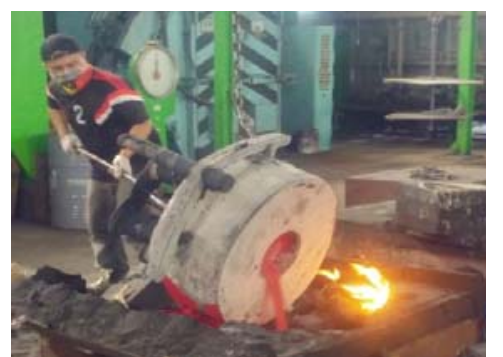

9. Shake out

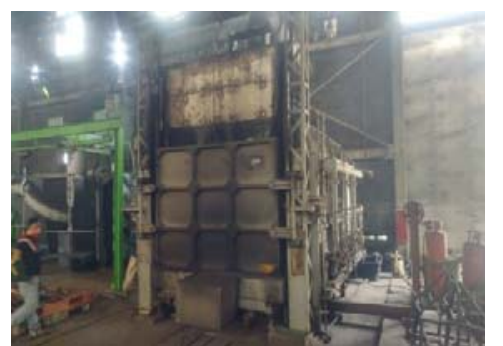

11. Normalising

Gambar 2. Urutan proses pembuatan support Roller dari proses pengecoran, ormalising hingga pemesinan 


\section{METODE PENELITIAN}

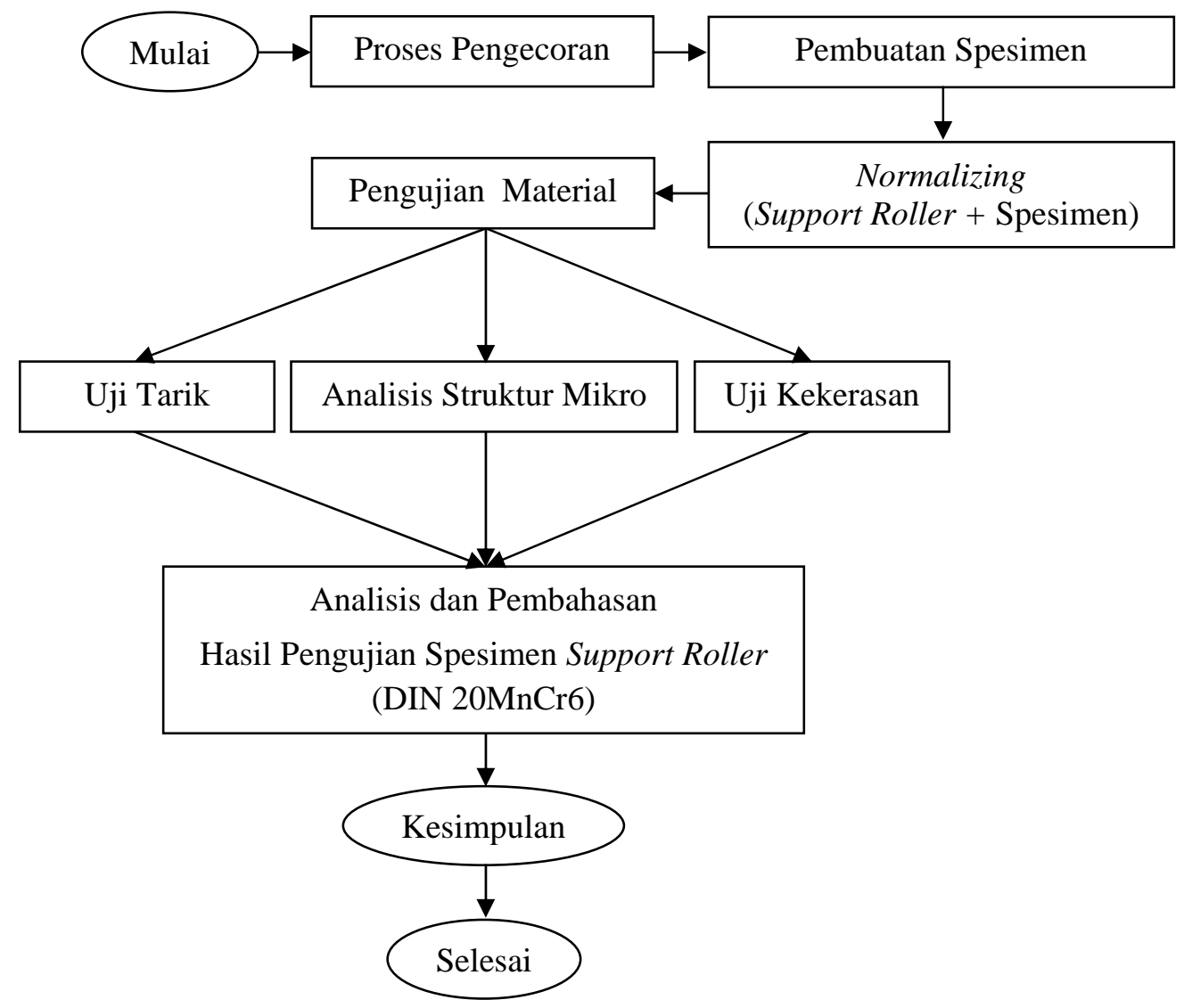

Gambar 3. Diagram penelitian

Normalizing dilakukan dengan pemanasan suhu mencapai $900^{\circ} \mathrm{C}$ dengan Holding Time selama 150 menit [2]. Dan kemudian didinginkan menggunakan pendinginan udara (normal) $30^{\circ} \mathrm{C}$ selama 7 jam seperti Gambar 4.

Selama proses pembuatan support roller ini dilakukan beberapa pengujian untuk melihat pengaruh normalizing terhadap pengecoran support roller dengan menggunakan dua spesimen untuk setiap pengujiannya. Spesimen ini digunakan untuk perbandingan antara produk normalizing dan tanpa normalizing.

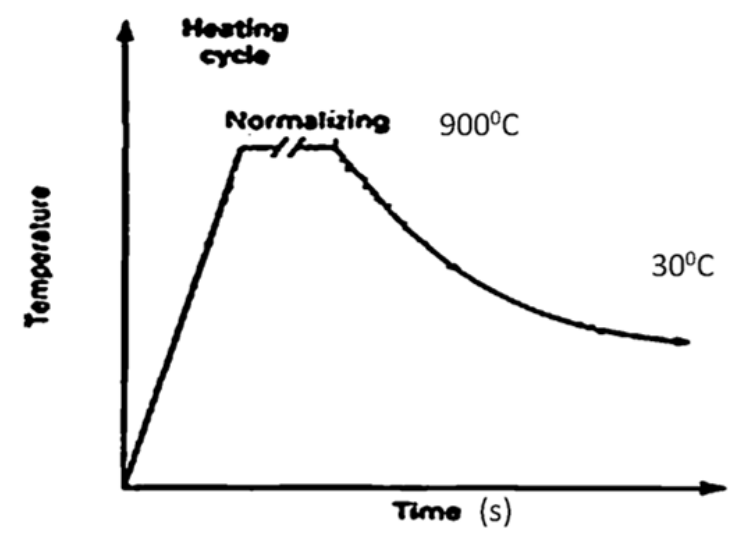

Gambar 4. Siklus pemanasan normalizing [3]

Normalizing biasanya digunakan pada baja carbon rendah dan plain carbon dengan tujuan memperhalus ukuran butir dan menghomogenitaskan struktur mikro dari hasil coran dan tempa, 
untuk meningkatkan mampu mesin dengan komposisi karbon sekitar 0,3\% C, dan memperhalus karbida kasar yang mempunyai presipitat [2].

\section{Tahap Pembuatan Spesimen}

Spesimen diambil dari material yang sama dengan produk casting yang dipisahkan saat proses penuangan (pouring). Dimana spesimen dituang ke cawan spesimen yang sudah disiapkan.

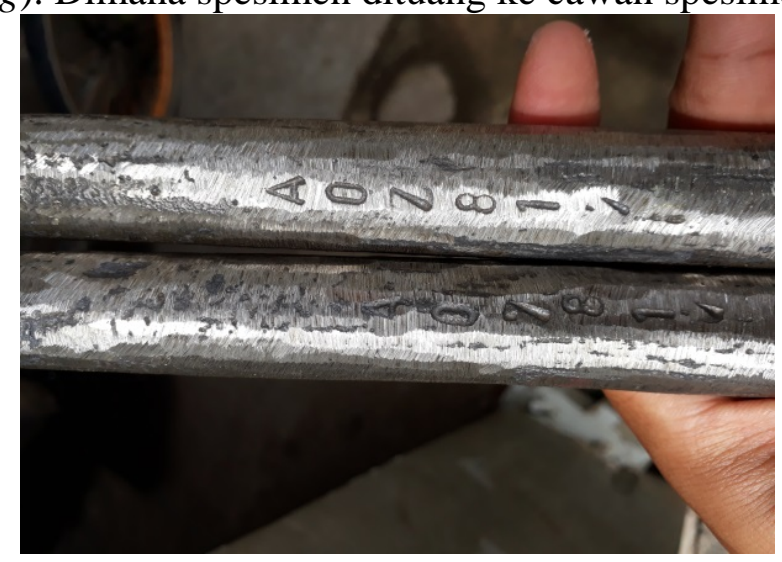

Gambar 5. Spesimen hasil casting

Spesimen pertama dibuat untuk pengujian tarik sesuai dengan dimensi yang sudah di standarkan (ASTM E8). Untuk membentuk spesimen sesuai standar dilakukan proses pemesinan yaitu bubut.
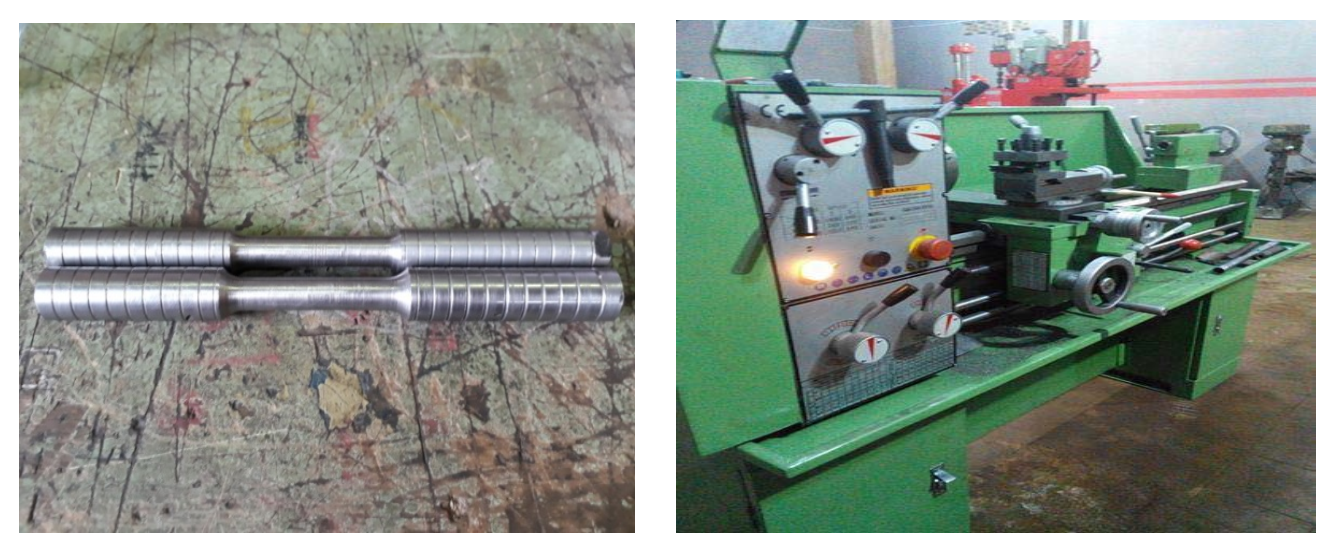

Gambar 6. Spesimen hasil pembubutan dan mesin bubut

Spesimen kedua dibuat untuk pengujian kekerasan dengan memotong spesimen casting menggunakan mesin potong dengan dimensi sesuai kebutuhan. Spesimen pengujian kekerasan juga dapat digunakan untuk pengujian analisis struktur mikro.

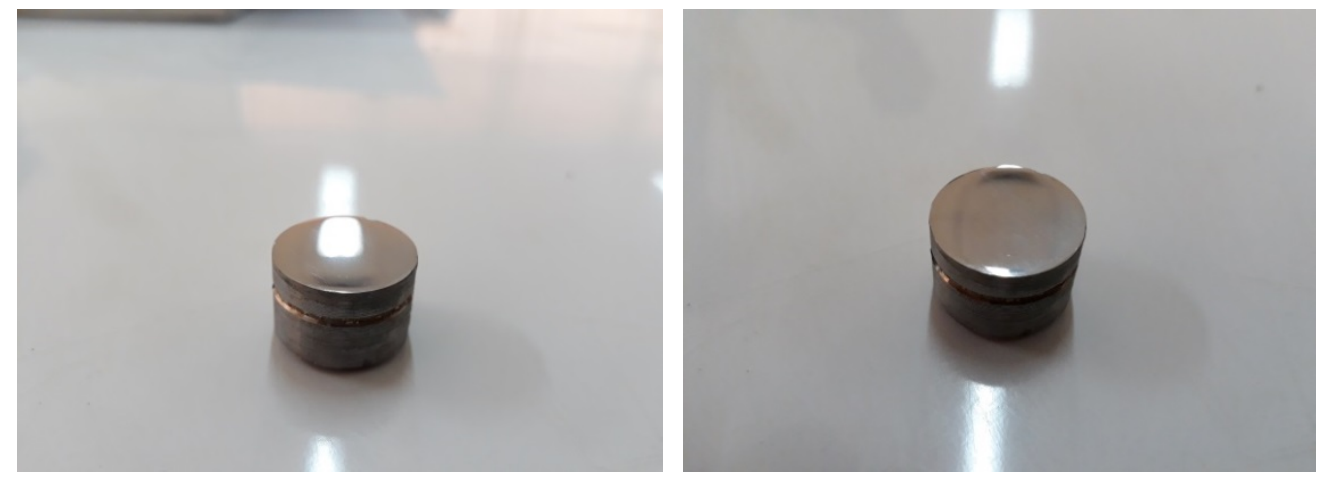

Gambar 7. Spesimen normalizing dan sebelum normalizing 


\section{Pengujian Tarik dan Kekerasan}

Pada pengujian ini dilakukan dua kali pengujian yaitu pada specimen sebelum dan setelah di normalizing pada saat pengecoran. Pembuatan spesimen pengujian harus mengacu kepada standar maka dari itu diperlukan proses pemesinan untuk mendapatkan dimensi yang diinginkan [4].
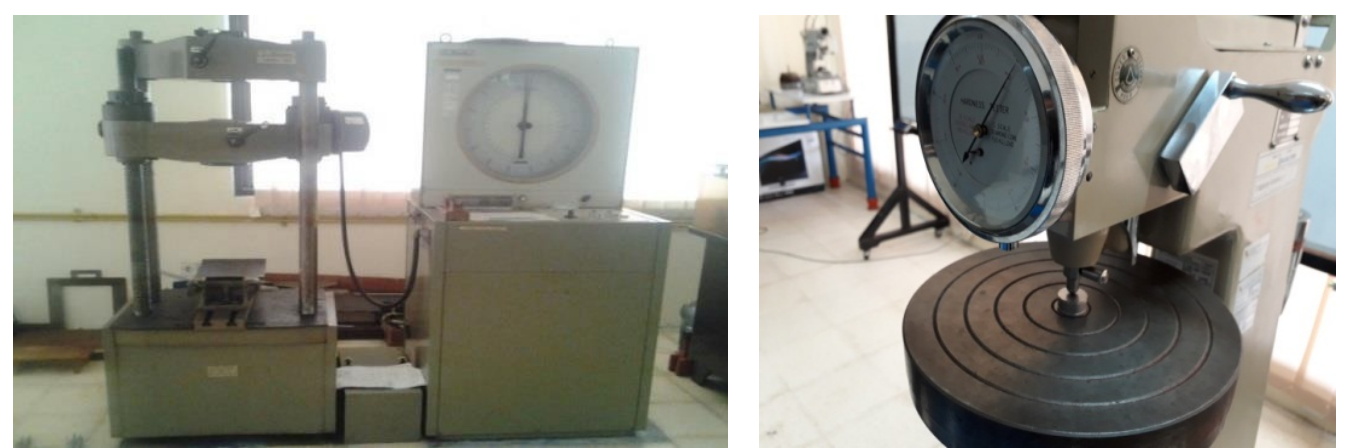

Gambar 8. Mesin uji tarik dan mesin uji keras Rockwell

Pada pengujian kekerasan digunakan mesin uji Rockwell dengan menggunakan skala B, dimana hasil ditunjukan dalam satuan HB setelah dikonversikan dari HRB yang dilakukan di laboratorium Dept. JPP .

\section{Pengujian Analisis Struktur Mikro}
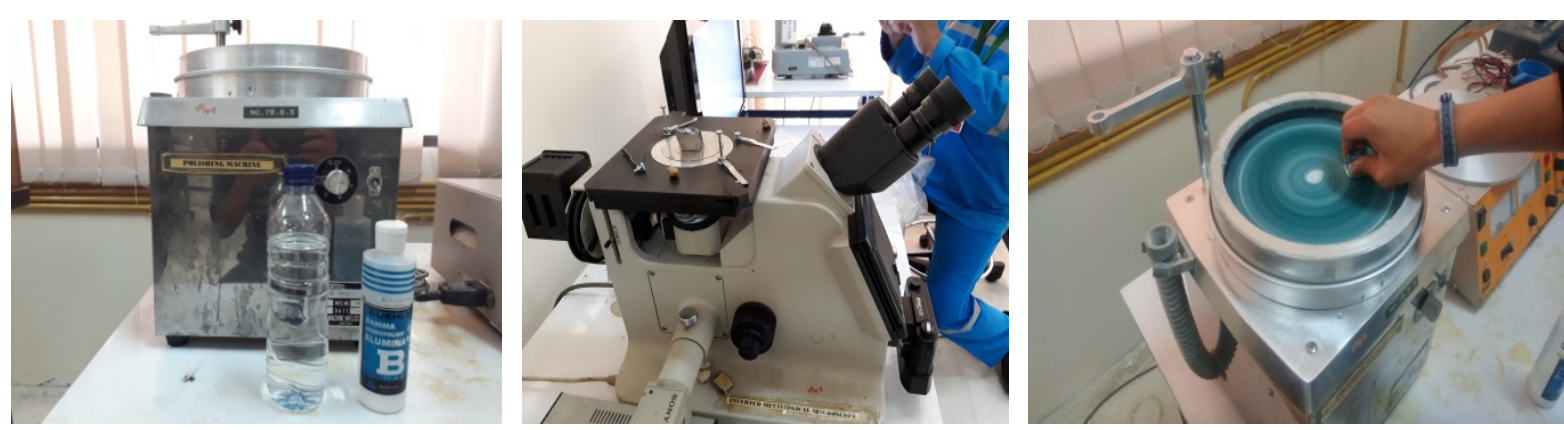

Gambar 9. Proses analisis struktur mikro

Struktur mikro dari baja cor dengan kadar karbon yang rendah terdiri dari ferrit dan perlit. Dari gambar terlihat bahwa penyebaran fasa perlit yang merata setelah normalizing di bandingkan dengan specimen yang tidak dinormalizing dapat dilihat pada Gambar 10.
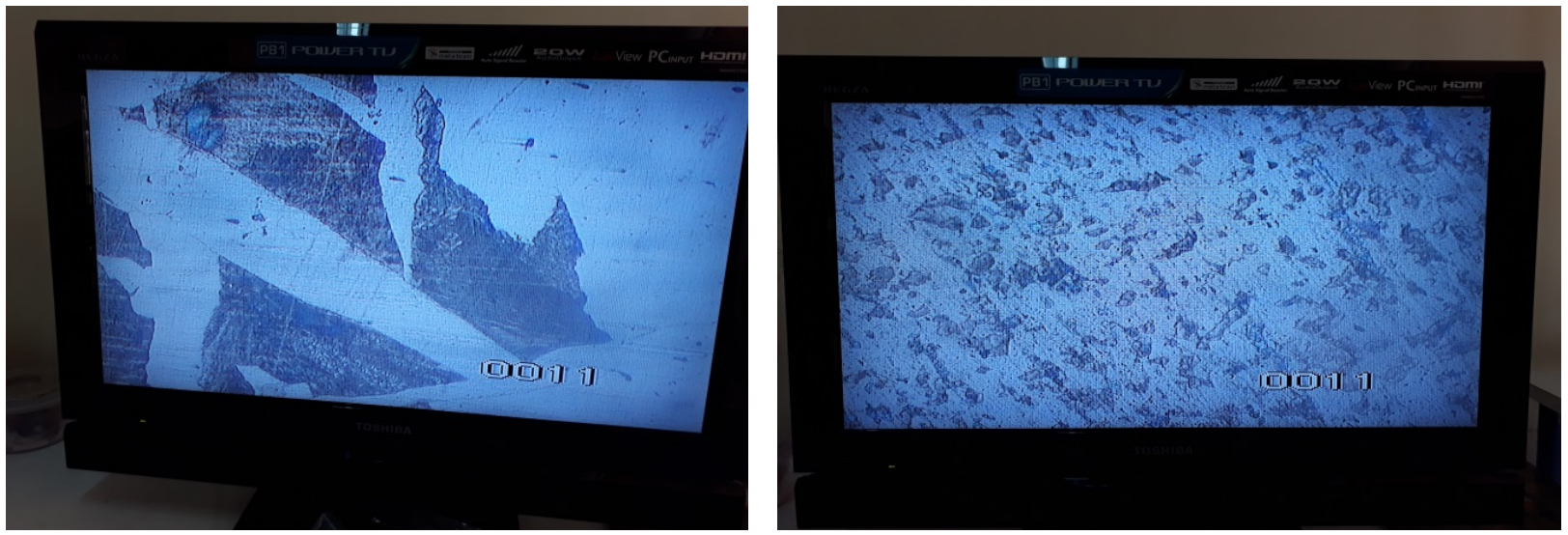

Gambar 10. Hasil analisis struktur mikro tanpa normalizing dan normalizing 


\section{HASIL DAN PEMBAHASAN}

Dari hasil uji tarik, kekuatan tarik dari baja cor setelah dinormalizing lebih rendah dari baja cor tanpa normalizing. Hal ini disebabkan karena penyebaran butir yang merata namun dengan jumlah yang sama.

Tabel 2. Hasil pengujian uji tarik

\begin{tabular}{cccccc}
\hline $\begin{array}{c}\text { No. } \\
\text { Speciment }\end{array}$ & Result & $\begin{array}{c}\text { Tensile } \\
\text { Strenght } \\
\left(\mathbf{K g f} / \mathbf{m m}^{2}\right)\end{array}$ & $\begin{array}{c}\text { Yield Strenght } \\
\left(\mathbf{K g f} / \mathbf{m m}^{2}\right)\end{array}$ & Elongation (\%) & $\begin{array}{c}\text { Reduction } \\
\text { Area (\%) }\end{array}$ \\
\hline A1 & Normalizing & 41,05 & 25,46 & 41,20 & 60,32 \\
A2 & Tanpa Normalizing & 42,16 & 29,52 & 29,52 & 37,53 \\
\hline
\end{tabular}

Dilihat dari bentuk patahannya spesimen yang di normalizing mengalami deformasi plastis sebelum patah, sebelum patah terjadi necking dan perpanjangan seperti pada Gambar 11, ini menunjukan bahwa hasil normalizing meningkatkan regangan (elongation), Semakin besar regangan maka meterial semakin ulet.
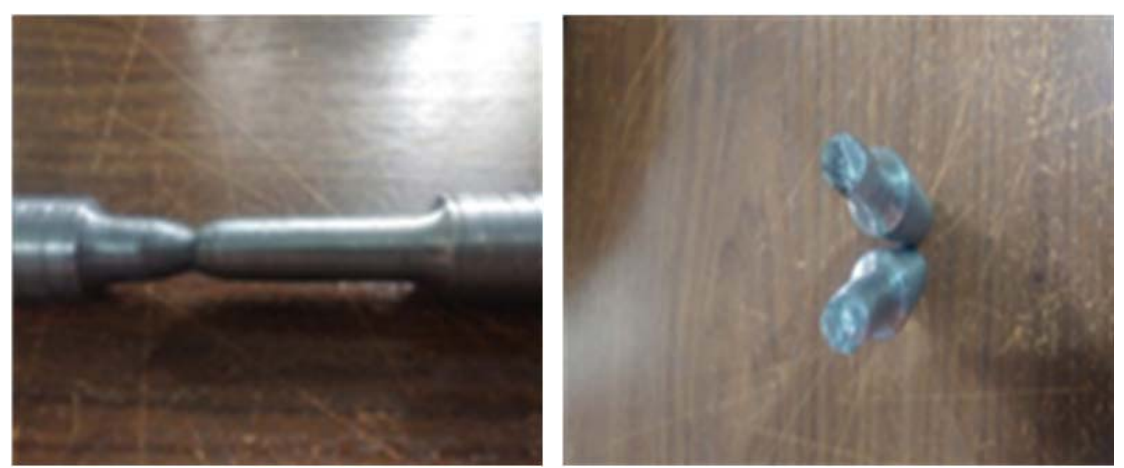

Gambar 11. Patahan hasil uji tarik spesimen hasil normalizing

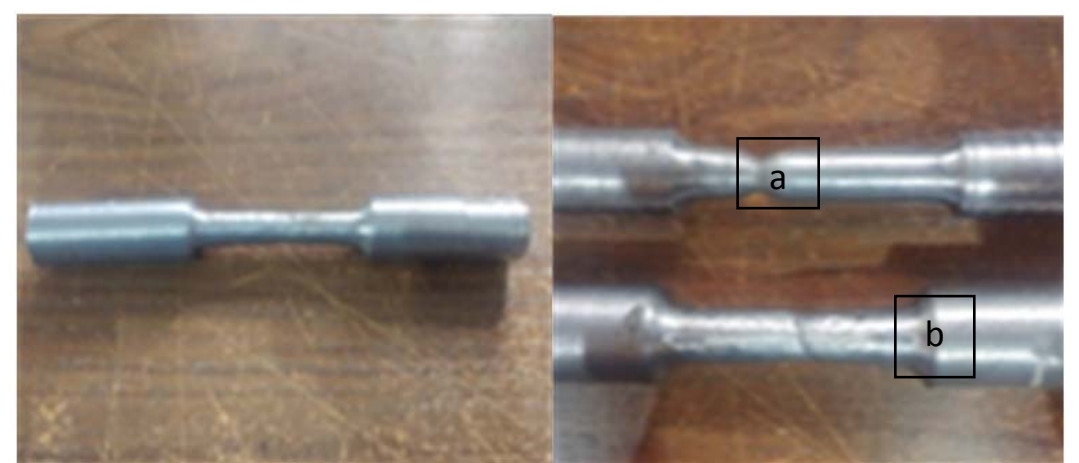

Gambar 12. Patahan hasil uji tarik spesimen yang yang mengalami normalizing (a) dan tidak di normalizing (b)

Patahan hasil uji tarik specimen yang tidak dinormalizing, tidak mengalami deformasi plastis dan langsung patah, artinya tidak terjadi necking atau perpanjang, dapat di simpulkan bahwa spesimenya yang tidak di normalizing bersifat getas.

\section{Hasil Pengujian Kekerasan}

Nilai kekerasan setelah normalizing menurun akibat dari penyebaran butir, hasil dari normalizing cenderung keras dan ulet. Material tanpa normalizing lebih keras karna waktu pendinginan yang cepat pada saat penuangan. 
Tabel 3. Rata rata harga kekerasan

\begin{tabular}{|c|c|c|}
\hline $\begin{array}{c}\text { No. } \\
\text { Speciment } \\
\end{array}$ & $\begin{array}{ll}\text { Proses } & \text { Result } \\
\end{array}$ & $\begin{array}{c}\text { Rata Rata } \\
\text { HRC (150kgf) }\end{array}$ \\
\hline A1 & Normalizing & 40 \\
\hline A2 & Tanpa Normalizing & 45 \\
\hline
\end{tabular}

Nilai kekerasan tanpa Normalizing juga tidak merata, di mana pada bagian permukaan lebih keras di banding bagian bawah permukaan, hal ini di sebabkan karena terjadi pembekuan yang tidak merata, dimana pembekuan pada permukaan dari hasil coran lebih cepat dibandingkan pada bagian dalam.

\section{SIMPULAN}

Dari pengujian yang dilakukan didapatkan bahwa proses normalizing, berpengaruh pada hasil pengecoran Baja 20MnCr6. Dibandingkan dengan specimen yang tidak dinormalizing, Kekerasan dan kekuatan Tarik hasil normalizing memang turun yaitu dari $42,16 \mathrm{kgf} / \mathrm{mm}^{2}$ menjadi $41,05 \mathrm{kgf} / \mathrm{mm}^{2}$, namun keuletan meningkat, yaitu dapat dilihat dari hasil elongasi dari 29,52\% menjadi 41,20\%. Selain itu truktur mikro hasil normalizing memiliki distribusi fasa yang merata hal ini juga mempengaruhi kerataan angka kekerasan pada setiap permukaan support Roller. Maka dapat disimpulkan proses normalising perlu dilakukan dalam proses pembuatan Support Roller untuk meningkatkan keuletannya.

\section{DAFTAR PUSTAKA}

[1]. Gotto, Eddy S. 2006. Modul Pelatihan Introduction To Casting Design Konstruksi Coran Dan Perancangan Pola. Bandung.

[2]. American Society for Metal 1985. Metal Hand Book, desk Edition. Ohio. Metal Park.

[3]. William D. Callister. JR.1992. Fundamental Of Material Science And Engineering, MC Graw Hill.

[4]. H.E. Davis., 1982. The Testing Of Engineering Materials, Mc Graw Hill.

[5]. Surdia, Tata. 2000. Teknik Pengecoran Logam. Jakarta: Pradnya.

[6]. Yusril, Irwan,2013,Proses Pengelasan,CV Hasba Jaya Bandung, ISBN 602891311-1. 